\title{
Effect of revascularization on cognitive outcomes in intracranial steno-occlusive disease: a systematic review
}

\author{
Bradley Kolb, BA, ${ }^{1}$ Hassan Fadel, BS, ${ }^{1}$ Gary Rajah, MD,, Hamidreza Saber, MD, ${ }^{2}$ Ali Luqman, MD, ${ }^{1}$ \\ and Leonardo Rangel-Castilla, MD ${ }^{3}$
}

\begin{abstract}
Departments of ${ }^{1}$ Neurosurgery and ${ }^{2}$ Neurology, Wayne State University, Detroit, Michigan; and ${ }^{3}$ Department of Neurosurgery, Mayo Clinic, Rochester, Minnesota
\end{abstract}

\begin{abstract}
OBJECTIVE Steno-occlusive diseases of the cerebral vasculature have been associated with cognitive decline. The authors performed a systematic review of the existing literature on intracranial steno-occlusive disease, including intracranial atherosclerosis and moyamoya disease (MMD), to determine the extent and quality of evidence for the effect of revascularization on cognitive performance.

METHODS A systematic search of PubMed/MEDLINE, the Thomson Reuters Web of Science Core Collection, and the $\mathrm{KCl}$ Korean Journal Database was performed to identify randomized controlled trials (RCTs) in the English-language literature and observational studies that compared cognitive outcomes before and after revascularization in patients with steno-occlusive disease of the intracranial vasculature, from which data were extracted and analyzed.

RESULTS Nine papers were included, consisting of 2 RCTs and 7 observational cohort studies. Results from 2 randomized trials including 142 patients with symptomatic intracranial atherosclerotic steno-occlusion found no additional benefit to revascularization when added to maximal medical therapy. The certainty in the results of these trials was limited by concerns for bias and indirectness. Results from 7 observational trials including 282 patients found some cognitive benefit for revascularization for symptomatic atherosclerotic steno-occlusion and for steno-occlusion related to MMD in children. The certainty of these conclusions was low to very low, due to both inherent limitations in observational studies for inferring causality and concerns for added risk of bias and indirectness in some studies.
\end{abstract}

CONCLUSIONS The effects of revascularization on cognitive performance in intracranial steno-occlusive disease remain uncertain due to limitations in existing studies. More well-designed randomized trials and observational studies are needed to determine if revascularization can arrest or reverse cognitive decline in these patients.

https://thejns.org/doi/abs/10.3171/2018.11.FOCUS18517

KEYWORDS stenosis; atherosclerosis; revascularization; endovascular; moyamoya; stent; bypass

\section{$\mathrm{T}$} HE major steno-occlusive diseases of the cerebral vasculature consist of moyamoya disease (MMD) and atherosclerotic disease of the large cerebral arteries. Both cause stenosis of the cerebral vasculature and subsequent cerebral hypoperfusion. This hypoperfusion has been associated with cognitive decline in cerebrovascular atherosclerosis. ${ }^{3,30,40}$ It has also been associated with cognitive decline in MMD. ${ }^{16-19,21,22,45}$ If the purported cognitive decline is caused by ongoing hypoperfusion rather than fixed ischemic injury, then revascularization could represent a means of reversing the cognitive decline..$^{31,46}$
Revascularization procedures for steno-occlusive disease consist of endovascular stent placement and open surgical arterial bypass, either direct extracranial-to-intracranial bypass (EC-IC bypass) or indirect encephaloduroarteriosynangiosis (EDAS). ${ }^{39}$ The utility of these procedures for halting or reversing the progression of steno-occlusive-associated cognitive decline has not been well-characterized and remains an open area of interest in the medical and surgical treatment of cerebrovascular disease. In order to address this question, we performed a systematic review of randomized controlled trials (RCTs) and high-quality

ABBREVIATIONS EC-IC = extracranial-intracranial; EDAS = encephaloduroarteriosynangiosis; ICA = internal carotid artery; $\mathrm{MCA}=$ middle cerebral artery; $\mathrm{MMD}=$ moyamoya disease; MoCA = Montreal Cognitive Assessment; RCT = randomized controlled trial; WAIS-R = Wechsler Adult Intelligence Scale-Revised; WISC-R = Wechsler Intelligence Scale for Children-Revised.

SUBMITTED September 30, 2018. ACCEPTED November 13, 2018.

INCLUDE WHEN CITING DOI: 10.3171/2018.11.FOCUS18517. 
observational studies comparing cognitive performance before and after revascularization in steno-occlusive cerebrovascular disease (Fig. 1).

\section{Methods}

A study protocol was drafted using the PRISMA (Preferred Reporting Items for Systematic Reviews and MetaAnalyses) guidelines. ${ }^{29}$ Studies were eligible for inclusion if they were observational studies of 5 or more individuals or RCTs published in the English-language literature between 2000 and the present. To identify relevant studies, we used the search term "TITLE:((cognitive OR neurocognitive OR cognition) AND (moyamoya OR (atheroscler* OR occlus* OR ischemia)))" to search PubMed/ MEDLINE, the Thomson Reuters Web of Science Core Collection, and the KCI Korean Journal Database for articles published in the English language between the years 2000 and 2018. Results of the search were screened for relevance by examining the title and abstracts. The resulting papers were reviewed in full and assessed against the predetermined inclusion and exclusion criteria. A standard form was created for data extraction and was filled out for each eligible study. For each study, the following variables were sought: description and selection of patient population, intervention, outcome assessed, baseline data, outcome data, and follow-up data. Qualitative and quantitative descriptions of each variable were recorded, whenever possible. We used the Grading of Recommendations



FIG. 1. Systematic review search strategy and review process.
Assessment, Development and Evaluation (GRADE) approach to rate the quality of evidence in each study and GRADEpro software (www.gradepro.org) to generate certainty estimates. ${ }^{4,14}$ The principal summary measure sought was difference in mean cognitive performance before and after revascularization, as measured by any validated assessment tool.

\section{Results}

\section{Study Selection}

After the initial search, 536 articles were returned. The article titles were screened for relevance, and irrelevant and duplicate articles were eliminated, resulting in 17 articles whose full text was assessed for eligibility. Five articles were excluded because they addressed revascularization for extracranial carotid artery stenosis. One article was a systematic review, one examined a nonoperative intervention, one did not compare pre- and postintervention cognitive performance, one examined combined intervention in patients with co-occurrence of external carotid artery stenosis with intracranial cerebrovascular disease, and one was an abstract. After eliminating these, 7 articles from the systematic search were included in the review itself. Two additional articles were added after searching the bibliographies of other included articles.

\section{Study Characteristics}

According to our search, there were 2 RCTs published in the English language between 2000 and September 2018 that addressed the question of whether revascularization affects cognitive performance in atherosclerotic cerebrovascular steno-occlusive disease. Turan et al. randomized 371 patients with recent transient ischemic attack or stroke attributable to $70 \%-99 \%$ intracranial stenosis to angioplasty and stenting with the Wingspan self-expanding stent plus best medical management versus best medical management alone, recording the Montreal Cognitive Assessment (MoCA) score at baseline, 4 months, 12 months, and at trial closeout. ${ }^{43}$ Marshall et al. randomized 41 patients with symptomatic internal carotid artery (ICA) occlusion and increased oxygen extraction fraction on PET to open surgery (EC-IC bypass) plus best medical management versus best medical management alone, comparing results on extensive neuropsychological testing prior to intervention and over the 2-year study follow-up period. ${ }^{31}$ See Table 1 for more information regarding these trials.

According to our search, 7 observational studies were published in the English-language literature between 2000 and September 2018 that address the question of whether revascularization affects cognitive performance in cerebrovascular steno-occlusive disease. Sasoh et al. observed 25 patients with hemodynamic cerebral ischemia attributable to unilateral ICA or middle cerebral artery (MCA) occlusion treated with open surgery (EC-IC bypass), comparing verbal, performance, and full-scale IQ scores as determined by the Wechsler Adult Intelligence Scale-Revised (WAIS-R) test preoperatively with results obtained 6 months after surgery. ${ }^{38}$ Dong et al. observed 9 patients with severe atherosclerotic steno-occlusive disease of the 


\begin{tabular}{|c|c|c|c|c|c|c|}
\hline & Question & Population & Intervention & Comparator & Outcome Assessed & Outcome Summary \\
\hline $\begin{array}{l}\text { Turan } \\
\text { et al., } \\
2017\end{array}$ & $\begin{array}{l}\text { Do angioplasty \& stenting, when } \\
\text { added to MMT, improve cognitive } \\
\text { function in pts w/ symptomatic } \\
\text { atherosclerotic high-grade stenosis } \\
\text { of the intracranial vasculature } \\
\text { compared w/ MMT alone? }\end{array}$ & $\begin{array}{l}59 \text { medical \& } 54 \\
\text { surgical pts re- } \\
\text { ceived } \geq 3 \text { yrs } \\
\text { of follow-up† }\end{array}$ & $\begin{array}{l}\text { Angioplasty \& } \\
\text { stenting w/ } \\
\text { the Wingspan } \\
\text { self-expanding } \\
\text { stent plus MMT }\end{array}$ & MMT & $\begin{array}{l}\text { MoCA score at baseline, } \\
4 \text { mos, } 12 \text { mos, \& at } \\
\text { trial closeout }(\sim 3 \text { yrs); } \\
\text { cognitive impairment } \\
\text { was defined as MoCA } \\
\text { score }<26\end{array}$ & $\begin{array}{l}\text { No significant } \\
\text { between-group } \\
\text { differences }\end{array}$ \\
\hline
\end{tabular}

MMT = maximal medical therapy; pts = patients.

* Forty-one adults with complete and symptomatic ICA occlusion, increased oxygen extraction fraction on PET, and no prior diagnosis of dementia were originally randomized. Two died, 2 were lost to follow-up, 2 refused 2-year testing, and 6 reached endpoints of the parent trial.

† Four hundred fifty-one patients with recent transient ischemic attack or stroke due to $70 \%-99 \%$ intracranial stenosis were randomized. Patients with stroke as the qualifying event with aphasia or neglect were excluded. Patients with a cerebrovascular event during follow-up were excluded from analysis. Only patients with full cognitive testing pre- and postintervention were included.

ICA or MCA treated with an EC-IC bypass, comparing pre- and postintervention performance on a neuropsychological battery of tests with performance observed in a cohort of 9 matched controls. ${ }^{11}$ Lee et al. observed 65 pediatric patients with MMD treated with EDAS, comparing performance on the Korean Educational Development Institute Wechsler Intelligence Scale for Children-Revised (WISC-R) before surgery with performance an average of 19 months after surgery. ${ }^{27}$ Fiedler et al. observed 40 patients with hemodynamic cerebral ischemia and occluded ICA treated with open surgery (EC-IC bypass), comparing IQ via WAIS-R testing preoperatively and at 12 months postsurgery. ${ }^{13}$ Baek et al. observed 5 adults with MMD treated with open surgery (EC-IC bypass), comparing performance on the Seoul Neuropsychological Screening Battery prior to surgery and within 3 months after surgery. ${ }^{2}$ Zeifert et al. observed 84 adults with MMD treated with open surgery (EC-IC bypass), comparing IQ scores via WAIS-R testing and a variety of other neuropsychological tests prior to surgery and at an average of 6.8 months after surgery. ${ }^{46} \mathrm{Kim}$ et al. observed 55 children with MMD treated with open surgery (EDAS), comparing IQ and other neuropsychological performance metrics prior to surgery and at an average of 11 months after surgery. ${ }^{24}$ See Table 2 for more information regarding these studies.

\section{Risk of Bias Within Studies}

Risk of bias, as well as overall assessments of the certainty of evidence offered by the studies addressed in our review, is summarized in Table 3 . We downgraded our certainty assessment of the 2 randomized trials included in this review due to what we assessed as a serious risk of bias in the study by Marshall et al. ${ }^{31}$ and serious risk of indirectness in that by Turan et al..$^{43}$ The question underlying our review of revascularization for intracerebral steno-occlusion is whether cognitive decline can be stopped or reversed by restoring the flow of oxygenated blood to ischemic brain tissue. In the Marshall et al. study, no patients in the surgical arm achieved an oxygen extraction fraction ratio $<1.067$ following surgical intervention, which was defined as the upper limit of normal in the parent study. As noted by the study authors, this raises concerns as to whether the surgical intervention achieved its ultimate goal of restoring perfusion to ischemic brain tissue, which would bias the results of the study toward medical intervention alone. ${ }^{31} \mathrm{We}$ concluded that there was a serious risk of indirectness in Turan et al. based on the study's use of MoCA scores to assess the cognitive performance of the study participants. As noted by the authors, the MoCA is used as a screening tool for cognitive impairment. In order to assess for the presence and extent of cognitive improvement, rather than just for the presence of cognitive impairment, we believe that more sensitive and extensive testing modalities are needed, such as the WAIS assessment deployed by Zeifert et al. ${ }^{46}$

In addition to the serious concerns just mentioned, there were other less serious concerns regarding risk of bias in both studies. In the Marshall et al. study, 6 of 19 (32\%) surgical patients randomized and 16 of $22(73 \%)$ medical patients randomized were not analyzed for various reasons, many of which were different from the reasons given for surgery patients. The direction of bias due to these missing outcome data is unpredictable. Additionally, there was some concern that, since participants were not blinded to their intervention due to the nature of the intervention itself, deviation from the prescribed medical therapy by the surgical treatment arm could also introduce bias into the results, favoring the medical treatment arm. Similar concerns regarding patient awareness of intervention were also present in Turan et al. The results of both studies are most likely robust to the potential bias associated with these concerns.

By their very nature, the observational studies included in this systematic review have a much higher risk of bias than the RCTs. The studies of Sasoh et al. ${ }^{38}$ and Fiedler et al..$^{13}$ were downgraded further due to concern for selec- 
TABLE 2. Characteristics of the observational studies

\begin{tabular}{|c|c|c|c|c|c|c|}
\hline & Question & Population & Intervention & Comparator & Outcome Assessed & Outcome Summary \\
\hline $\begin{array}{l}\text { Sasoh } \\
\text { et al., } \\
2003\end{array}$ & $\begin{array}{l}\text { How does performance on IQ } \\
\text { tests } 6 \text { mos after intervention } \\
\text { compare to preintervention } \\
\text { performance? }\end{array}$ & $\begin{array}{l}25 \text { adults w/ unilat } \\
\text { athero-occlusive } \\
\text { ICA or MCA } \\
\text { disease }\end{array}$ & $\begin{array}{l}\text { EC-IC } \\
\text { bypass }\end{array}$ & NC & $\begin{array}{l}\text { WAIS-R verbal, perfor- } \\
\text { mance, FSIQ } 2 \text { wks } \\
\text { before \& } 6 \text { mos after } \\
\text { intervention }\end{array}$ & $\begin{array}{l}\text { SSI in mean } V I Q, P I Q, \& \\
\quad F S I Q\end{array}$ \\
\hline $\begin{array}{l}\text { Lee et al., } \\
\qquad 2011\end{array}$ & $\begin{array}{l}\text { How does performance on IQ } \\
\text { tests an average of } 19 \text { mos } \\
\text { after intervention compare to } \\
\text { preintervention performance? }\end{array}$ & 65 children w/ MMD & EDAS & $\mathrm{NC}$ & KEDI-WISC-R & $\begin{array}{l}\text { SSI in mean PIQ but not } \mathrm{VIQ} \\
\text { or FSIQ }\end{array}$ \\
\hline $\begin{array}{l}\text { Fiedler et } \\
\quad \text { al., } 2011\end{array}$ & $\begin{array}{l}\text { How does performance on IQ } \\
\text { tests } 12 \text { mos after interven- } \\
\text { tion compare to preinterven- } \\
\text { tion performance? }\end{array}$ & $\begin{array}{l}20 \text { adults w/ unilat } \\
\text { atherosclerotic } \\
\text { occlusion of the } \\
\text { ICA }\end{array}$ & $\begin{array}{l}\text { EC-IC } \\
\text { bypass }\end{array}$ & NC & WAIS-R & $\begin{array}{l}\text { SSI in IQ, number collection } \\
\text { test, \& trail making test; } \\
4 \text { other cognitive tests } \\
\text { showed no improvement }\end{array}$ \\
\hline $\begin{array}{l}\text { Dong et } \\
\quad \text { al., } 2012\end{array}$ & $\begin{array}{l}\text { How does performance on an } \\
\text { extensive neuropsychological } \\
\text { screening battery } 3-6 \text { mos } \\
\text { after intervention compare to } \\
\text { preintervention performance? }\end{array}$ & $\begin{array}{l}9 \text { pts w/ high-grade } \\
\text { atherosclerotic } \\
\text { stenosis of the } \\
\text { intracranial ICA or } \\
\text { MCA }\end{array}$ & $\begin{array}{l}\text { EC-IC } \\
\text { bypass }\end{array}$ & $\begin{array}{r}9 \text { matched } \\
\text { controls }\end{array}$ & $\begin{array}{l}7 \text { cognitive domain } \\
\text { neuropsychological } \\
\text { battery of tests }\end{array}$ & $\begin{array}{l}\text { Between-group SSI in mea- } \\
\text { sures of verbal memory \& } \\
\text { executive function }\end{array}$ \\
\hline $\begin{array}{l}\text { Baek et al., } \\
2014\end{array}$ & $\begin{array}{l}\text { How does performance on an } \\
\text { extensive neuropsychological } \\
\text { screening battery w/in } 3 \text { mos } \\
\text { of intervention compare to } \\
\text { preintervention performance? }\end{array}$ & $\begin{array}{l}5 \text { female adults } w / \\
\text { MMD }\end{array}$ & $\begin{array}{l}\text { EC-IC } \\
\text { bypass }\end{array}$ & NC & $\begin{array}{l}\text { Seoul Neuropsycho- } \\
\text { logical Screening } \\
\text { Battery }\end{array}$ & $\begin{array}{l}\text { SSI in verbal \& visual } \\
\text { memory; no improvement } \\
\text { in } 6 \text { other aspects of neu- } \\
\text { ropsychological battery } \\
\text { administered }\end{array}$ \\
\hline $\begin{array}{l}\text { Zeifert et } \\
\quad \text { al., } 2017\end{array}$ & $\begin{array}{l}\text { How does performance on IQ } \\
\text { tests an average of } 6.8 \text { mos } \\
\text { after intervention compare to } \\
\text { preintervention performance? }\end{array}$ & $\begin{array}{l}84 \text { consecutive } \\
\text { adults w/ MMD }\end{array}$ & $\begin{array}{l}\text { EC-IC } \\
\text { bypass }\end{array}$ & NC & WAIS-R & $\begin{array}{l}\text { No improvement in IQ scores } \\
\text { of } 86 \% \text { of participants, w/ } \\
8 \% \text { showing significant } \\
\text { decline \& } 6 \% \text { showing a } \\
\text { significant improvement }\end{array}$ \\
\hline $\begin{array}{l}\text { Kim et al., } \\
\qquad 2018\end{array}$ & $\begin{array}{l}\text { How does performance on IQ } \\
\text { tests an average of } 11 \text { mos } \\
\text { after intervention compare to } \\
\text { preintervention performance? }\end{array}$ & 55 children w/ MMD & EDAS & NC & $\begin{array}{l}\text { Korean WISC-III, other } \\
\text { neuropsychological } \\
\text { tests }\end{array}$ & $\begin{array}{l}\mathrm{SSI} \text { in FSIQ \& PIQ but no } \\
\text { improvement in VIQ }\end{array}$ \\
\hline
\end{tabular}

$\mathrm{FSIQ}=$ full-scale IQ; KEDI-WISC-R = Korean Educational Development Institute WISC-R; NC = no comparator; $\mathrm{PIQ}$ = performance IQ; SSI = statistically significant improvement; $\mathrm{VIQ}=$ verbal $I Q$.

tion bias, since neither study explained how surgical candidates were selected. The Fiedler et al. study was also downgraded for imprecision, since this paper only presented summary statistics regarding cognitive outcomes, with no individual data points.

\section{Results of Individual Studies}

Marshall et al. found no additional cognitive performance benefit from EC-IC bypass when added to best medical therapy in their 2014 randomized study of symptomatic intracranial atherosclerosis patients. ${ }^{31}$ Turan et al. also found no additional cognitive performance benefit from intercranial stenting when added to best medical therapy in their 2017 randomized study of symptomatic intracranial atherosclerosis patients. This study was an offshoot of the SAMMPRIS (Stenting Versus Aggressive Medical Therapy for Intracranial Arterial Stenosis) trial, which compared stenting plus best medical therapy with best medical therapy alone in the prevention of stroke and death in patients with symptomatic atherosclerotic disease of the intracranial circulation. ${ }^{6,43}$
With respect to intracranial atherosclerotic disease treated with an EC-IC bypass, 3 observational studies reported positive results. Sasoh et al. observed statistically significant increases in verbal, performance, and fullscale IQ scores in their cohort of 25 patients. ${ }^{38}$ Fiedler et al. observed statistically significant increases in IQ scores in their cohort of 20 patients with atherosclerotic occlusion of the ICA 12 months after EC-IC bypass..$^{13}$ They did not present descriptive data for their findings. Dong et al. observed statistically significant between-group improvement postintervention in measures of verbal memory and executive function $(\mathrm{p}=0.043)$, and a nonsignificant improvement in visual memory compared with controls $(\mathrm{p}=$ 0.052). Importantly, statistically significant improvements were not durable to adjustment for multiple comparisons. ${ }^{11}$

With respect to MMD, 4 studies reported data. Lee et al. observed no statistically significant differences in preand postsurgery full-scale and verbal IQ scores, but they did observe a statistically significant increase in performance IQ in children with MMD treated with EDAS. ${ }^{27}$ Interestingly, the authors noted that even preoperative per- 
TABLE 3. Certainty and outcome assessments

\begin{tabular}{|c|c|c|c|c|c|c|c|c|c|}
\hline \multicolumn{7}{|c|}{ Certainty Assessment } & \multirow[b]{2}{*}{ Outcome Assessment } & \multirow[b]{2}{*}{ Certainty } & \multirow[b]{2}{*}{ Importance } \\
\hline $\begin{array}{l}\text { No. of } \\
\text { Studies }\end{array}$ & $\begin{array}{l}\text { Study } \\
\text { Design }\end{array}$ & $\begin{array}{l}\text { Risk of } \\
\text { Bias }\end{array}$ & Inconsistency & Indirectness & Imprecision & $\begin{array}{c}\text { Other } \\
\text { Considerations }\end{array}$ & & & \\
\hline 2 & $\begin{array}{l}\text { Randomized } \\
\text { trials }\end{array}$ & Serious* & NS & Serious† & NS & None & $\begin{array}{l}142 \text { pts randomized to revascular- } \\
\text { ization, either by EC-IC bypass } \\
\text { (Marshall et al.) or by angioplasty } \\
\text { plus expandable stenting (Turan } \\
\text { et al.); cognitive assessment was } \\
\text { done at baseline \& at follow-up } \\
\text { using either a neuropsychologi- } \\
\text { cal battery of tests ( } 29 \text { pts) or the } \\
\text { MoCA (113 pts). No significant } \\
\text { between-group differences were } \\
\text { found }\end{array}$ & Low & Critical \\
\hline
\end{tabular}

Does cognitive performance in patients w/ MMD improve after surgical revascularization? (follow-up range 3-46 mos; assessed w/ cognitive tests)

4 Observation- NS NS NS NS None Observation of 65 children (Lee et Low Important
$\begin{array}{ll}\text { al studies } & \text { al.) \& } 84 \text { adults W/ MMD (Zeifert }\end{array}$

et al.) treated with EDAS \& EC-IC

bypass, respectively, found no

significant differences in pre- \&

postintervention FSIQ; converse-

ly, observation of 55 children

w/ MMD (Kim et al.) treated w/

EDAS found significant improve-

ment in postintervention FSIQ. A

small cohort of 5 adult females

w/ MMD treated w/ EC-IC bypass

(Baek et al.) showed significant

improvement in 2 of 8 tests in

a neuropsychological battery

(visual \& verbal memory)

Does cognitive performance in patients w/ atherosclerotic steno-occlusive disease improve following surgical revascularization? (follow-up range 3-12 mos; assessed w/ cognitive tests)

2 Observation- Serious $\ddagger$ NS NS Serious§ None Observation in 25 adults (Sasoh et Very low Important al studies

al.) found a 5.9-point improvement in mean $\mathrm{VIQ}, 6.5$-point improvement in mean FIQ, \& 6.5-point improvement in mean FSIQ; observation in 40 adults reported significant improvement in multiple cognitive tests, but no data were published (Fiedler et al.)

Does cognitive performance in patients with atherosclerotic steno-occlusive disease improve compared to untreated controls following surgical revascularization? (follow-up range 3-6 mos; assessed w/ Mini-Mental Status Examination, MoCA, neuropsychological battery)

$\begin{array}{ccccc}\begin{array}{c}\text { Observation- NS NS NS N } \\ \text { al studies }\end{array} & & \text { None } & \begin{array}{c}\text { Observation of } 9 \text { adults found sig- } \\ \text { nificant improvement compared } \\ \end{array} \\ & & \text { W/ matched controls in verbal } \\ & \text { memory \& executive function } \\ & & \text { scores }\end{array}$

NS = not serious.

* In Marshall et al., no patients in the surgical arm achieved oxygen extraction fraction ratio < 1.067, which was the upper limit of normal defined for the parent study, raising concerns that the results of this study were biased by the failure of procedural success in the surgical arm.

$\dagger$ Assessment measures such as Montreal Cognitive Assessment may be insufficient to detect actual improvements in cognitive function.

$\ddagger$ Neither Sasoh et al. nor Fiedler et al. provide an explanation for how surgical candidates were chosen from larger cohorts of symptomatic patients.

$\S$ Fiedler et al. does not provide data regarding cognitive outcomes, only summary statistics. 
formance on all IQ domains was within the average range for age-appropriate societal controls. Following Lee et al., Kim et al. also reported a statistically significant improvement in performance IQ score, and this difference was large enough to result in a significant increase in full-scale IQ. ${ }^{24}$ Baek et al. observed a statistically significant increase in performance on verbal and visual memory components of the Seoul Neuropsychological Screening Battery in their cohort of 5 patients with MMD 3 months after EC-IC bypass. ${ }^{2}$ They found no statistically significant differences in the 6 other aspects of the Seoul Neuropsychological Screening Battery. Of note, they observed a 9-standard deviation improvement in performance on visuospatial testing in one patient, raising some concern for the reliability of testing in general with respect to outliers. Zeifert et al. observed no significant change in WAIS-R IQ scores in $86 \%$ of their cohort of 84 patients with MMD evaluated an average of 6.8 months after EC-IC bypass. ${ }^{46}$ Evaluation of change was done using so-called reliable change indices obtained from prior published research. Using this metric, significant improvement was observed in $6 \%$ of patients, and significant decline was observed in $8 \%$ of patients.

\section{Discussion}

We performed a systematic review of the literature on the effects of revascularization on cognitive performance in intracranial steno-occlusive disease. We found 2 RCTs indicating that revascularization plus best medical therapy does not improve cognitive function more than best medical therapy alone in atherosclerotic steno-occlusive disease, but the certainty of this conclusion was low due to concern for risk of bias and indirectness. These conclusions also conflict with 3 observational studies, which all report cognitive improvement after surgical revascularization in patients with intracranial atherosclerotic stenoocclusive disease. Four observational studies examining cognitive performance following surgical revascularization in patients with MMD were found, with data from 2 of these studies suggesting that intervention may improve IQ in children treated with EDAS due to improvement in performance IQ. The certainty of this conclusion is low, however, due to the inherent limitations in observational studies.

Steno-occlusion has also been associated with cognitive impairment in extracranial steno-occlusive disease. For example, the Asymptomatic Carotid Stenosis and Cognitive Function study evaluated cognitive function in 82 patients with $>49 \%$ asymptomatic carotid stenosis and 60 nonstenotic controls with matched vascular comorbidities, education status, estimated intelligence, and depressive symptoms, finding a statistically significant reduction in both composite cognitive function and domain-specific learning/memory and motor/processing function in the stenotic group. ${ }^{26}$ The authors also measured reduced cerebrovascular reserve in stenotic patients and hypothesized that the reduction in cognitive performance seen in these patients is due to hypoperfusion in the context of insufficient collaterals. A recent systematic review and metaanalysis reaffirmed the effectiveness of endarterectomy for symptomatic stenosis. ${ }^{36}$ The effect of revascularization, by either endarterectomy or stenting, on cognition in extracranial atherosclerotic disease has also been addressed by multiple systematic reviews. ${ }^{1,37}$ Plessers et al. found a large variation in patient selection, presence or absence of control groups, modality of assessment, and timing of assessment, making it difficult to establish definitive conclusions regarding the cognitive benefit of stenting or endarterectomy. ${ }^{37}$ Antonopoulos and colleagues were slightly more optimistic, reporting an association between carotid artery stenting and improvement in global cognition, memory, attention, and psychomotor speed. ${ }^{1}$ However, they also noted that stenting did not seem to be associated with improvements in executive function, language, or functional ability. Heller and Hines, in their recent review, concluded only that revascularization for carotid stenosis may provide cognitive benefit in patients with clinically significant disorders. ${ }^{15}$

An important future direction for the study of the effects of intracranial and extracranial revascularization on cognitive outcomes involves understanding how to better identify subgroups of high-risk patients. The SAMMPRIS trial demonstrated that in patients with symptomatic intracranial stenosis, maximal medical therapy is superior to angioplasty and stenting using the Wingspan system for ischemic event prevention in both the short and long term. ${ }^{6,10,44}$ However, recent data have suggested that stenting is at least comparably effective and possibly superior to maximal medical therapy when patient selection is optimized to include only patients at a high risk of ischemic events. ${ }^{7,33}$ If true, this may suggest that the original outcome of the SAMMPRIS trial was confounded by the inclusion of low-risk patients. Studies finding no additional cognitive benefit to revascularization over and above maximal medical therapy such as Marshall et al. ${ }^{31}$ and Turan et al. ${ }^{43}$ may be similarly confounded. If only patients with high-grade cognitive impairment and high risk of further deterioration are studied, it may be the case that surgical or endovascular intervention offers a durable advantage compared with medical therapy. Further investigation of revascularization outcomes with the Wingspan system (Post Market Surveillance Study of the Wingspan Stent System trial, registration no. NCT02034058, clinicaltrials.gov) is being carried out at 26 locations across the United States and may demonstrate improved outcomes compared with the SAMMPRIS trial. Submaximal angioplasty has also been shown to safely improve vessel diameters and may offer an additional endovascular avenue for future study in this area. ${ }^{12}$

The identification of at-risk subgroups of patients with steno-occlusion requires the development of novel screening and diagnostic modalities. Floating a pressure guidewire across a region of intracranial stenosis as a means of measuring fractional flow reserve (FFR, maximal blood flow in a stenotic artery divided by normal maximal flow in a nonstenotic artery) may represent a superior way of assessing cerebral ischemia when compared with angiographic evaluation. ${ }^{32}$ Data from randomized trials in interventional cardiology showed that using FFR as opposed to angiographic assessment to guide endovascular intervention resulted in a significant reduction in the composite endpoint of death, nonfatal myocardial infarction, and re- 
peat revascularization at 1 year. ${ }^{42}$ A trial assessing the cognitive effects of revascularization in patients chosen using FFR would be a welcome addition to the literature. Transcranial Doppler monitoring has also proven beneficial in identifying patients at high risk of ischemic events. ${ }^{41} \mathrm{~A}$ recent review suggested that arterial stiffness, as measured by various surrogates such as pulse-wave velocity, cardioankle vascular index, ankle-brachial index, pulse pressure, augmentation index, flow-mediated dilation, carotid intima media thickness, and arterial stiffness index-beta, is a sensitive indicator of cognitive impairment. ${ }^{28}$ Further work should investigate whether measures of arterial stiffness can be useful in identifying patients who would benefit cognitively from revascularization. Pulsed arterial spin-labeling perfusion MRI has been used to demonstrate that patients with Alzheimer's disease have significantly greater regional hypoperfusion than cognitively normal subjects in multiple regions of the brain, including the cingulate gyrus, the superior and middle frontal gyri, and the inferior parietal lobe. These observations are also supported by findings with FDG PET and ${ }^{99 m}$ Tc HMPAO (hexamethylpropyleneamine oxime) SPECT, which have demonstrated reduced cerebral metabolism and blood flow in patients with Alzheimer's disease, respectively. ${ }^{20}$ These modalities may represent further means of stratifying patient cohorts in order to identify subgroups that would best benefit from revascularization.

The focus on identification of subgroups amenable to intervention has also received recent attention in the literature on extracranial revascularization. Dempsey and colleagues recently demonstrated that ultrasound-measured plaque strain can be used to measure carotid plaque instability and may offer a more useful metric for assessing risk in carotid atherosclerosis patients than degree of stenosis alone. ${ }^{9}$ The same group has reported the preservation of cognition 1 year after endarterectomy in patients with prior cognitive decline, with improvement predicted by the presence of hypertension and lower preexisting cognitive decline prior to intervention. ${ }^{8}$ In similar work, CasasHernanz and coauthors recently used bivariate analysis in an attempt to identify properties separating "cognitive responders" to carotid revascularization from "non-responders," concluding that cognitive responders were younger patients without fixed neurological deficits or anatomical changes such as atrophy or white matter changes due to small vessel disease. ${ }^{5}$ These studies suggest that earlier intervention may have cognitive benefit in select subgroups of patients in the case of extracranial atherosclerotic disease, and a similar situation may hold true in the case of intracranial atherosclerotic disease.

With respect to MMD, our systematic review found observational evidence from 2 relatively large cohorts that EDAS may improve performance IQ in children. ${ }^{24,27}$ The certainty of this finding is low, due to inherent limitations with observational studies. Although a well-designed clinical trial testing the effects of revascularization versus conservative treatment in children with MMD would help settle the issue, this may be ethically difficult given previous data suggesting that revascularization has a benefit in preventing stroke and hemorrhage in MMD over and above any benefit to cognitive performance. ${ }^{34,39}$ In the case of revascularization for adults with MMD, further work on patient stratification and selection would seem to be critical. Recent work has demonstrated that intellectual and memory impairment in adults with MMD, while possible in the absence of stroke, may in fact be quite limited in general. $^{21,22}$ Furthermore, work by Miyoshi and colleagues demonstrated stable normal cognitive function over a 2-year course in adult MMD patients. ${ }^{35}$ Recent work has also shown a significant population of individuals with asymptomatic MMD, raising further questions about the exact nature of cognitive impairment in MMD. ${ }^{25}$ In this context, it is not necessarily surprising that revascularization was shown to have limited beneficial effects on cognition in the largest and most recent study of adult MMD patients. ${ }^{46}$ Clearly, further work is needed to unravel the natural history of MMD as well as to identify adult MMD patients who might benefit most from revascularization. ${ }^{23}$

\section{Limitations}

This systematic review was limited to articles published in the English language from 2000 to 2018. Although multiple databases were used and a systematic search of bibliographies was employed to supplement search terms, incomplete retrieval of relevant articles is possible.

\section{Conclusions}

The current evidence for the effect of revascularization on cognitive outcomes in intracranial steno-occlusive diseases is of low certainty. Further well-designed trials are needed to both determine the extent to which revascularization improves cognitive performance in intracranial steno-occlusive disease and identify subpopulations in which revascularization may be particularly effective.

\section{References}

1. Antonopoulos CN, Kakisis JD, Sfyroeras GS, Moulakakis KG, Kallinis A, Giannakopoulos T, et al: The impact of carotid artery stenting on cognitive function in patients with extracranial carotid artery stenosis. Ann Vasc Surg 29:457469, 2015

2. Baek HJ, Chung SY, Park MS, Kim SM, Park KS, Son HU: Preliminary study of neurocognitive dysfunction in adult moyamoya disease and improvement after superficial temporal artery-middle cerebral artery bypass. J Korean Neurosurg Soc 56:188-193, 2014

3. Bakker FC, Klijn CJ, Jennekens-Schinkel A, van der Tweel I, Tulleken CA, Kappelle LJ: Cognitive impairment in patients with carotid artery occlusion and ipsilateral transient ischemic attacks. J Neurol 250:1340-1347, 2003

4. Balshem H, Helfand M, Schünemann HJ, Oxman AD, Kunz R, Brozek J, et al: GRADE guidelines: 3. Rating the quality of evidence. J Clin Epidemiol 64:401-406, 2011

5. Casas-Hernanz L, Garolera M, Badenes D, Quintana S, Millán S, Calzado N, et al: Neuropsychological outcome one year after carotid revascularization: a before-and-after study. Vasc Spec Int 33:146-155, 2017

6. Chimowitz MI, Lynn MJ, Derdeyn CP, Turan TN, Fiorella D, Lane BF, et al: Stenting versus aggressive medical therapy for intracranial arterial stenosis. N Engl J Med 365:993-1003, 2011

7. Cui XP, Lin M, Mu JS, Ye JX, He WQ, Fu ML, et al: Angioplasty and stenting for patients with symptomatic intracranial atherosclerosis: study protocol of a randomised controlled trial. BMJ Open 6:e012175, 2016 
8. Dempsey RJ, Jackson DC, Wilbrand SM, Mitchell CC, Berman SE, Johnson SC, et al: The preservation of cognition 1 year after carotid endarterectomy in patients with prior cognitive decline. Neurosurgery 82:322-328, 2018

9. Dempsey RJ, Varghese T, Jackson DC, Wang X, Meshram $\mathrm{NH}$, Mitchell CC, et al: Carotid atherosclerotic plaque instability and cognition determined by ultrasound-measured plaque strain in asymptomatic patients with significant stenosis. J Neurosurg 128:111-119, 2018

10. Derdeyn CP, Chimowitz MI, Lynn MJ, Fiorella D, Turan TN, Janis LS, et al: Aggressive medical treatment with or without stenting in high-risk patients with intracranial artery stenosis (SAMMPRIS): the final results of a randomised trial. Lancet 383:333-341, 2014

11. Dong Y, Teoh HL, Chan BP, Ning C, Yeo TT, Sinha AK, et al: Changes in cerebral hemodynamic and cognitive parameters after external carotid-internal carotid bypass surgery in patients with severe steno-occlusive disease: a pilot study. J Neurol Sci 322:112-116, 2012

12. Dumont TM, Sonig A, Mokin M, Eller JL, Sorkin GC, Snyder KV, et al: Submaximal angioplasty for symptomatic intracranial atherosclerosis: a prospective Phase I study. J Neurosurg 125:964-971, 2016

13. Fiedler J, Přibáň V, Skoda O, Schenk I, Schenková V, Poláková S: Cognitive outcome after EC-IC bypass surgery in hemodynamic cerebral ischemia. Acta Neurochir (Wien) 153:1303-1312, 2011

14. Guyatt GH, Oxman AD, Vist GE, Kunz R, Falck-Ytter Y, Alonso-Coello P, et al: GRADE: an emerging consensus on rating quality of evidence and strength of recommendations. BMJ 336:924-926, 2008

15. Heller S, Hines G: Carotid stenosis and impaired cognition: the effect of intervention. Cardiol Rev 25:211-214, 2017

16. Hogan AM, Kirkham FJ, Isaacs EB, Wade AM, Vargha-Khadem F: Intellectual decline in children with moyamoya and sickle cell anaemia. Dev Med Child Neurol 47:824-829, 2005

17. Hogan AM, Pit-ten Cate IM, Vargha-Khadem F, Prengler M, Kirkham FJ: Physiological correlates of intellectual function in children with sickle cell disease: hypoxaemia, hyperaemia and brain infarction. Dev Sci 9:379-387, 2006

18. Imaizumi C, Imaizumi T, Osawa M, Fukuyama Y, Takeshita M: Serial intelligence test scores in pediatric moyamoya disease. Neuropediatrics 30:294-299, 1999

19. Ishii R, Takeuchi S, Ibayashi K, Tanaka R: Intelligence in children with moyamoya disease: evaluation after surgical treatments with special reference to changes in cerebral blood flow. Stroke 15:873-877, 1984

20. Johnson NA, Jahng GH, Weiner MW, Miller BL, Chui HC, Jagust WJ, et al: Pattern of cerebral hypoperfusion in Alzheimer disease and mild cognitive impairment measured with arterial spin-labeling MR imaging: initial experience. Radiology 234:851-859, 2005

21. Karzmark P, Zeifert PD, Bell-Stephens TE, Steinberg GK, Dorfman LJ: Neurocognitive impairment in adults with moyamoya disease without stroke. Neurosurgery 70:634-638, 2012

22. Karzmark P, Zeifert PD, Tan S, Dorfman LJ, Bell-Stephens TE, Steinberg GK: Effect of moyamoya disease on neuropsychological functioning in adults. Neurosurgery 62:10481052,2008

23. Kazumata K, Ito M, Uchino H, Nishihara H, Houkin K: Proposal for a prospective registry for Moyamoya disease in Japan. Neurol Med Chir (Tokyo) 57:66-72, 2017

24. Kim W, Lee EY, Park SE, Park EK, Kim JS, Kim DS, et al: Neuropsychological impacts of indirect revascularization for pediatric moyamoya disease. Childs Nerv Syst 34:11991206,2018

25. Kuroda S: Asymptomatic moyamoya disease: literature re- view and ongoing AMORE study. Neurol Med Chir (Tokyo) 55:194-198, 2015

26. Lal BK, Dux MC, Sikdar S, Goldstein C, Khan AA, Yokemick J, et al: Asymptomatic carotid stenosis is associated with cognitive impairment. J Vasc Surg 66:1083-1092, 2017

27. Lee JY, Phi JH, Wang KC, Cho BK, Shin MS, Kim SK: Neurocognitive profiles of children with moyamoya disease before and after surgical intervention. Cerebrovasc Dis 31:230-237, 2011

28. Li X, Lyu P, Ren Y, An J, Dong Y: Arterial stiffness and $\operatorname{cog}$ nitive impairment. J Neurol Sci 380:1-10, 2017

29. Liberati A, Altman DG, Tetzlaff J, Mulrow C, Gøtzsche PC, Ioannidis JP, et al: The PRISMA statement for reporting systematic reviews and meta-analyses of studies that evaluate healthcare interventions: explanation and elaboration. BMJ 339:b2700, 2009

30. Marshall RS, Festa JR, Cheung YK, Chen R, Pavol MA, Derdeyn CP, et al: Cerebral hemodynamics and cognitive impairment: baseline data from the RECON trial. Neurology 78:250-255, 2012

31. Marshall RS, Festa JR, Cheung YK, Pavol MA, Derdeyn CP, Clarke WR, et al: Randomized Evaluation of Carotid Occlusion and Neurocognition (RECON) trial: main results. Neurology 82:744-751, 2014

32. Miao Z, Liebeskind DS, Lo W, Liu L, Pu Y, Leng X, et al: Fractional flow assessment for the evaluation of intracranial atherosclerosis: a feasibility study. Intervent Neurol 5:6575,2016

33. Miao Z, Zhang Y, Shuai J, Jiang C, Zhu Q, Chen K, et al: Thirty-day outcome of a multicenter registry study of stenting for symptomatic intracranial artery stenosis in China. Stroke 46:2822-2829, 2015

34. Miyamoto S, Yoshimoto T, Hashimoto N, Okada Y, Tsuji I, Tominaga T, et al: Effects of extracranial-intracranial bypass for patients with hemorrhagic moyamoya disease: results of the Japan Adult Moyamoya Trial. Stroke 45:1415-1421, 2014

35. Miyoshi K, Chida K, Kobayashi M, Kubo Y, Yoshida K, Terasaki K, et al: Two-year clinical, cerebral hemodynamic, and cognitive outcomes of adult patients undergoing medication alone for symptomatically ischemic moyamoya disease without cerebral misery perfusion: a prospective cohort study. Neurosurgery [epub ahead of print], 2018

36. Orrapin S, Rerkasem K: Carotid endarterectomy for symptomatic carotid stenosis. Cochrane Database Syst Rev 6:CD001081, 2017

37. Plessers M, Van Herzeele I, Vermassen F, Vingerhoets G: Neurocognitive functioning after carotid revascularization: a systematic review. Cerebrovasc Dis Extra 4:132-148, 2014

38. Sasoh M, Ogasawara K, Kuroda K, Okuguchi T, Terasaki $\mathrm{K}$, Yamadate K, et al: Effects of EC-IC bypass surgery on cognitive impairment in patients with hemodynamic cerebral ischemia. Surg Neurol 59:455-463, 2003

39. Scott RM, Smith ER: Moyamoya disease and moyamoya syndrome. N Engl J Med 360:1226-1237, 2009

40. Silvestrini M, Paolino I, Vernieri F, Pedone C, Baruffaldi $\mathrm{R}$, Gobbi B, et al: Cerebral hemodynamics and cognitive performance in patients with asymptomatic carotid stenosis. Neurology 72:1062-1068, 2009

41. Spence JD: Transcranial Doppler monitoring for microemboli: a marker of a high-risk carotid plaque. Semin Vasc Surg 30:62-66, 2017

42. Tonino PA, De Bruyne B, Pijls NH, Siebert U, Ikeno F, van' t Veer M, et al: Fractional flow reserve versus angiography for guiding percutaneous coronary intervention. N Engl J Med 360:213-224, 2009

43. Turan TN, Smock A, Cotsonis G, Bachman D, Al Kasab S, Lynn MJ, et al: Is there benefit from stenting on cognitive function in intracranial atherosclerosis? Cerebrovasc Dis 43:31-35, 2017 
44. Wabnitz A, Chimowitz M: Angioplasty, stenting and other potential treatments of atherosclerotic stenosis of the intracranial arteries: past, present and future. J Stroke 19:271276, 2017

45. Williams TS, Westmacott R, Dlamini N, Granite L, Dirks P, Askalan R, et al: Intellectual ability and executive function in pediatric moyamoya vasculopathy. Dev Med Child Neurol 54:30-37, 2012

46. Zeifert PD, Karzmark P, Bell-Stephens TE, Steinberg GK, Dorfman LJ: Neurocognitive performance after cerebral revascularization in adult moyamoya disease. Stroke 48:15141517, 2017

\section{Disclosures}

The authors report no conflict of interest concerning the materials or methods used in this study or the findings specified in this paper.

\section{Author Contributions}

Conception and design: all authors. Acquisition of data: Kolb, Fadel, Rajah. Analysis and interpretation of data: Kolb, Fadel, Rajah. Drafting the article: Kolb, Rajah. Critically revising the article: Rangel-Castilla, Kolb, Rajah, Saber, Luqman. Reviewed submitted version of manuscript: Kolb. Statistical analysis: Kolb.

\section{Correspondence}

Leonardo Rangel-Castilla: Mayo Clinic, Rochester, MN. rangelcastilla.leonardo@mayo.edu. 